Queerying Families of Origin. Chiara Bertone and Maria Pallotta-Chiarolli (Eds.). New York, NY: Routledge. 2015. 248 pp. ISBN 978-1-138-82910-7. \$160.00. Hardcover.

Fifteen years ago, Robert-Jay Green published a critique of the prevailing wisdom surrounding lesbians and gay men in families of origin. In this work, Green (2000) called attention to the overgeneralization of findings from studies of White, North American, upperand middle-class lesbians and gays; recruitment primarily from PFLAG (Parents, Families, and Friends of Lesbians and Gays) and other groups that are likely to be uniquely accepting; and failure to analyze the social and cultural contexts in which family interactions unfold, among other theoretical and methodological issues. The trouble, Green noted, is not merely the skewed picture we develop as a result, but how this picture informs clinical practice, and the labeling of certain choices, such as coming out to family members, as more psychologically healthy and mature than others. Many of these same critiques are raised by Chiara Bertone and Maria Pallotta-Chiarolli in their important new volume, Queerying Families of Origin, which highlights the unfortunate persistence of these problems into the 21 st century. Although we have seen an explosion of lesbian, gay, and queer scholarship, and we have pushed boundaries and "queered" the family along many dimensions, the study of sexuality within families of origin remains comparatively narrow in its scope. Indeed, Bertone and Pallotta-Chiarolli open the book by highlighting "the gaps between the richness of research on GLBT lives, including experiences of intimacy and parenthood, and the paucity of research on their relations with their families of origin" (p. 1). This edited collection is one of the first systematic attempts to address the issues raised by Green at the turn of the century and to map future directions and innovations in the field.

This is the author manuscript accepted for publication and has undergone full peer review but has not been through the copyediting, typesetting, pagination and proofreading process, which may lead to differences between this version and the Version of Record. Please cite this article as doi: $10.1111 /$ jftr.12129

This article is protected by copyright. All rights reserved. 
Throughout the volume, an overarching question asks how we might move from a focus on familial acceptance and normative support from a position of heterosexual privilege to alliances based on shared stories of family diversity. Toward this end, the editors emphasize the fluidity, heterogeneity, and contradictions inherent in the (heterosexual) family as an institution. They refuse to see lesbian or gay and heterosexual families as distinct and polarized objects of inquiry, inviting us, instead, to examine how all members of the family are positioned in relation to multiple intersecting power relations. In this and other ways, the volume taps into the potential of family-of-origin research to inform multiple fields of study, beyond tropes of "coming out" and familial acceptance that have dominated the literature. In this review, I briefly outline the structure and key contributions of the volume, identify areas for continued growth in the scholarship on queer families of origin, and conclude by reflecting on the transformation of dominant models and paradigms through innovative comparative work.

\section{STRUCTURE AND CONTRIBUTIONS}

The book is composed of the editors' introduction, 10 empirical research chapters spanning continents and disciplines, and a concluding essay by Esther Rothblum surveying this research in relation to the developing field of GLBTQ family studies. The introduction is itself a significant work, not only in framing the contents of the volume but also in reimagining the possibilities for queer family-of-origin research. Some of these possibilities are borne out in the chapters, and others point to areas that remain underexamined, such as the inclusion of a wider range of kin relationships, alternative methods for reaching family members who are not connected to PFLAG-style organizations in their respective countries, 
and impacts of colonization and decolonization on queer families of origin in many parts of the world.

The empirical chapters constitute a diverse tapestry of queer family life woven together by strong connective threads. I focus on five of these threads, pulling examples of each from throughout the book. First, I note contributions to the study of parent-child relations, focusing on the "cultural tool kits" parents draw from to make sense of their children's sexuality (Martin, Hutson, Kazyak, \& Scherrer, 2010). Next, I briefly acknowledge the regional focus, interdisciplinarity, and intersectionality that I believe represent the volume's unique strengths. I conclude this section by highlighting bisexual, transgender, and gender nonconforming perspectives, as these have received comparatively little attention in the larger body of scholarship on queer family-of-origin relationships.

Parent-child relations are a major focus of the volume, addressed to some degree in every chapter. These vary with regard to whether we learn about the relationship from the (adult) children (chapters by Svab \& Kuhar; Glass; Watson; Capellato \& Mangarella), from the parents themselves (chapters by Grafsky; Bertone \& Franchi; Johnson \& Benson; Platero), or from a mixed orientation sample (Malici). Data from the Family Matters Study analyzed by Bertone and Franchi (Chapter 4) and Capellato and Mangarella (Chapter 11) include interviews with both parents and their children, although these multifamily perspectives are not highlighted in the chapters.

Among the more original findings related to parent-child relations are those that identify the culturally and contextually specific discourses utilized by parents. The fourth chapter by Bertone and Franchi is notable in this regard, analyzing how Italian parents of lesbian and gay children use Catholic discourses to make sense of their children's sexuality. 
Parents in this study marshal discourses of Christian love, mercy, suffering, and the figure of Mary Magdalene to distance themselves from the church's official stance on homosexuality while maintaining a sense religious belonging. The authors situate these narratives in the wider context of Italian Catholicism and therapeutic culture. Their findings hold implications for lesbian and gay studies as well as for studies of religion and family change in Italy. As this case demonstrates, more contextual approaches are needed to connect queer family-oforigin research to a broader set of questions and issues within family studies and other fields. In a second example from the volume, Malici (Chapter 10) investigates the intersections of queer media representations, TV viewing practices, and familial interactions in Italian households. Malici focuses on the "queer TV moments" that occur when family members, often gathered in the living room, confront GLBT characters and narratives on television. This chapter offers a refreshing approach to queer representation, situated in the Italian social and political context and linked to daily interactions and rituals. The chapter effectively bridges audience research with notions of queer temporality and "queer moments" that disrupt heteronormative logic in the family sphere.

As these examples show, the chapters are cross-continental in scope with a strong regional focus, including studies conducted in Australia (Watson), Canada (Baldo, focusing on Italian-immigrant families), Italy (Bertone \& Franchi; Malici; Cappellato \& Mangarella), Slovenia (Svab \& Kuhar), Spain (Platero), and the United States (Glass; Grafsky; Johnson \& Benson). The focus on Southern Europe is a strength of the collection. This is not merely an issue of diversity or representation. Rather, it is an opportunity to develop more rigorous theory and practice suitable to varying social and cultural contexts. The editors note in 
particular the value of Southern European perspectives for the study of intergenerational relations, given the close-knit cross-generational ties that are characteristic of this region.

In addition, the volume offers and inspires a more interdisciplinary conversation about sexuality and family-of-origin relationships. Existing research primarily attends to the psychological dimensions of parental reactions to disclosure and pathways to acceptance of a lesbian or gay child. Historical, humanistic, sociological, and other approaches are needed to complement and expand on this body of work. Baldo's analysis of the film Mambo Italiano (Chapter 9) illustrates the value of such approaches. Baldo combines migration and diaspora studies and family resiliency studies with a close reading of the film to show how two Italian Canadian families creatively negotiate the coming out of their sons. She argues that the tools and resources of immigration, including ritual and ethnic adaptation, become the very strategies these families use to integrate gayness into the family.

The intersectionality at the heart of Baldo's analysis is present in other chapters as well. Glass (Chapter 5) explores the ways Black lesbian couples in the United States emphasize and de-emphasize different aspects of their identity as they navigate family-oforigin and extended family rituals, daily rituals together as a couple, and commitment ceremonies. Many of her participants de-emphasized their lesbian sexuality to maintain connections to valued family and community rituals while also creating privatized rituals to honor their multiple identities. Platero (Chapter 8) writes about the intersectionality of race, class, and parenting for a Roma family raising a gender-nonconforming child in a housing project in Spain. The mother of this family observed that teachers and professionals often struggled to communicate with her about her son's femininity because of stereotypes they held of Roma culture and their assumptions about how a Roma person would react to gender- 
nonconforming behaviors. Similar stereotypes and assumptions arise in more covert ways in Watson's study of bisexuality in Australia (Chapter 6). Although many informants (including those of White European origin) describe deeply conservative family backgrounds, this conservatism is racialized for East Asian and South Asian informants, as when described as a characteristic of Asian culture. Although not explicitly mentioned by the author, this pattern points to ways in which queer narratives may reinforce racial hierarchies and controlling images.

Watson's study is among the first to delve into bisexual family-of-origin relationships and to draw from interviews with sex and gender diverse informants (including men, women, transgender, cross-dressing, genderqueer, and intersex individuals). On the basis of these interviews, Watson identifies "a generative ethics of bisexual becomings" (p. 120) emerging through wider socio-discursive contexts, with the family-of-origin as a pivotal domain. Subsequent chapters by Johnson and Benson (Chapter 7) and Platero (Chapter 8) take us into the lives of a single mother of a transgender child in a rural US community, and parents of gender-nonconforming and trans youth in Spain, respectively. Johnson and Benson assess the therapeutic environment for their informant as she navigates multiple forms of marginalization, stemming from her role as the parent of a six-year-old transgender child and her social location as a single mother. Platero considers how parents interact with educational, health, and social work professionals, often educating these professionals about genderissues even as they reach out for support and information. Collectively, these three chapters provide crucial variation in family experiences based on sexual and gender identification and embodiment. They also highlight bisexual, trans, and gendernonconforming family studies as areas for continued growth. It is my hope that one day, the 
inclusion of such perspectives will not be a key contribution or strength (as I have framed it here) but rather the status quo within queer family-of-origin research.

\section{AREAS FOR GROWTH}

Despite its own careful critique, the volume is not able to entirely evade an overemphasis on "coming out" and pathways to parental acceptance. Many of the interventions the authors make are revisions rather than reconstructions of existing models, for example, the "transparent closet," the "family closet," and the processual and relational components of coming out to one's kin. Each of these puts a new spin on "coming out of the closet" as an affective and relational experience. However, the closet remains a central trope. This is visible in Rothblum's conclusion as well, where the first major themes identified are that "coming out to the family is pivotal" (p. 232) and "coming out changes the family system" (p. 233). On the one hand, this is likely due to the importance of "coming out" to the subjects themselves; one could argue that the researchers are simply writing about what they observe in the empirical world. On the other hand, it is likely also shaped by engagement with the existing literature, which focuses disproportionately on sexual identity and disclosure, and by the types of questions asked of participants as a result.

The vision put forth by the editors inspires a bigger shift — it calls for new questions, framed by different theories altogether. Further work is needed to integrate queer family-oforigin research with a larger body of scholarship on family life and family change. For example: How do queer families of origin fit within the literatures on motherhood, fatherhood, the global circulation of parenting discourses, the intersections of family with law and medicine, and other demographic and family trends (to name but a few of the possible areas to explore)? 
A related area for growth, also noted by the editors, is the lack of gender analysis surrounding heterosexual family members. Understanding how gender shapes family experiences of queer sexuality is crucial in the move to contextualize and historicize families of origin. There is surprisingly little attention to gender differences among heterosexual family members in the bulk of the scholarship on queer families of origin, despite the deeply gendered nature of family roles, relationships, and hierarchies. In my work, for example, I have found that mothers' strategies for rearing lesbian, gay, and queer children are profoundly shaped by the conditions of gender inequality in their own lives (Brainer, 2015). Svab and Kuhar (Chapter 2) and Johnson and Benson (Chapter 7) touch on this briefly in their discussion of parental coping strategies, noting that patriarchal cultures hold mothers disproportionately responsible for child outcomes. Building from these examples, we need more research on the variation in mothering and fathering queer children, on how gender and generation shape sibling experiences in these families, and on other forms of difference and inequality within family units.

One of the most intriguing contributions the volume promises to make is introduced on the second page, where "putting families of origin into the queer picture" (the title of the introduction) is recognized as a way of "queerying . . . the very distinction between the families GLBT people come from (families of origin), and the ones they create (families of choice), by questioning the (hetero)normative assumptions about forms and boundaries of family this distinction rests upon." Are families of origin themselves "queered" in this volume? We are certainly invited to rethink many of our assumptions about these families. But the distinction lingers, and in many cases, queer sexualities are recouped through 
heteronormative discourses and processes of "familization," which leave the forms and boundaries of the family relatively intact.

This brings us full circle to the editors' framing question, mentioned at the outset of this review, about ways to reimagine family alliances beyond more privileged and normative forms of advocacy. The research studies presented in this book offer fresh angles for viewing many dimensions of queer family life and relationships. At the same time, like any fruitful project, the book raises as many questions as it answers. "Queerying" the distinction between families of origin and choice is one such question, which is sure to engender further research.

\section{TRANSFORMING MODELS}

I remember clearly the anticipation I felt when I first encountered this collection of essays, originally published as a special issue of Journal of GLBT Family Studies. The release of this special issue in 2013 coincided with the culmination of 16 months of ethnographic fieldwork that I had conducted with queer people and their families of origin throughout Taiwan. In situating my own work in the literature, I was frequently disappointed by the disconnect I perceived between GLBT family-of-origin research and the wealth of scholarship on the social, historical, and cultural transformation of family life regionally and globally. Thus, the vision put forth by Bertone and Pallotta-Chiarolli, toward a more intersectional, theoretically rich, and critically queer analysis of families of origin, resonated with me immediately.

As I explored this edited collection, I found many themes emerging from Southern Europe to be directly relevant and relatable to my work in Taiwan. Such connections point to the generative potential of comparative research among underrepresented social and cultural contexts, dislodging the United States (and other Anglophone Western countries) as the default comparative case. What might we learn by integrating our analyses of queer families 
of origin across Asia, Africa, Latin America, and the Middle East? Or among underrepresented groups within the global north and families elsewhere?

The importance of social location and geographic specificity cannot be overstated, and this observation should not be read as a call for a global or "universal" theory of queer family-of-origin relationships. At the same time, we have much to gain from a cross-national and cross-cultural dialogue about the limits of dominant models and paradigms. For example, Glass's description of how Black lesbians do not cut ties with extended families but rather integrate their partners into the family as "fictive kin" (Chapter 5) is similar to practices observed among gay men and lesbians in Singapore (Tan, 2011) and China (Kam, 2013). The strategic use of silence among queer people and their families in Slovenia (Svab \& Kuhar, Chapter 2) might be productively compared to the negotiation of visibility, invisibility, and silence surrounding sexual nonconformity in US Latino families (Acosta, 2011). Svab and Kuhar also mention that a majority of their Slovenian informants coreside with their parents. Researchers in Turkey (Wimark, 2015) and Hong Kong (Tang, 2011), among other places, have written about the impact of intergenerational coresidence on queer family-of-origin relationships. When each of these studies is individually contrasted with data collected on White, middle-class families in Anglophone Western countries (e.g., United States, United Kingdom, Canada, Australia), the former are often interpreted as examples of "difference" or variation from dominant models and theories, which retain their normative power in such an equation. However, when read together, these cases turn the norm on its head, often showing the difference or variance to be, instead, the prevailing wisdom about sexuality and families based on the Anglophone Western samples. In this way, comparative work among 
underrepresented groups will contribute to the larger epistemological project of decentering the West and revealing its cultural specificity.

The value of this shift is captured in a sentence drawn from the volume's abstract: "A focus on marginal contexts, such as southern Europe, and on marginal subjects, like bisexuals or black lesbians, is proposed as a way to challenge the universality of privileged narratives within heteronormativity, homonormativity, and Anglo-centrism, and to reveal unexpected resources families of origin mobilize to make sense of GLBT identities and lived experiences." This is an ambitious project, and one that does not disappoint. As much as the volume makes good on its promise to challenge privileged narratives and reveal unexpected family resources, it also points to areas for growth that are sure to inspire continued innovations in the field.

\section{REFERENCES}

Acosta, K. (2011). The language of (in)visibility: Using in-between spaces as a vehicle for empowerment in the family. Journal of Homosexuality, 58(6-7), 883-900.

Brainer, A. (2015). Mothering gender and sexually nonconforming children in Taiwan.

Journal of Family Issues. Advance online publication. doi: $10.1177 / 0192513 X 15598549$

Green, R. J. (2000). Lesbians, gay men, and their parents: A critique of LaSala and the prevailing clinical wisdom. Family Process, 39(2), 257-266.

Kam, L. Y. L. (2012). Shanghai lalas: Female Tongzhi communities and politics in urban China. Hong Kong: Hong Kong University Press. 
Martin, K. A., Hutson, D. J., Kazyak, E., \& Scherrer, K. S. (2010). Advice when children come out: The cultural "tool kits" of parents. Journal of Family Issues, 31(7), 960991.

Tan, C. K. K. (2011). Go home, gay boy! Or, why do Singaporean gay men prefer to "go "home" and not "come out"? Journal of Homosexuality, 58(6-7), 865-882.

Tang, D. T. S. (2011). Conditional spaces: Hong Kong lesbian desires and everyday life.

Hong Kong: Hong Kong University Press.

Wimark, T. (2015). The impact of family ties on the mobility decisions of gay men and lesbians. Gender, Place \& Culture: A Journal of Feminist Geography. doi: 10.1080/0966369X.2015.1034246

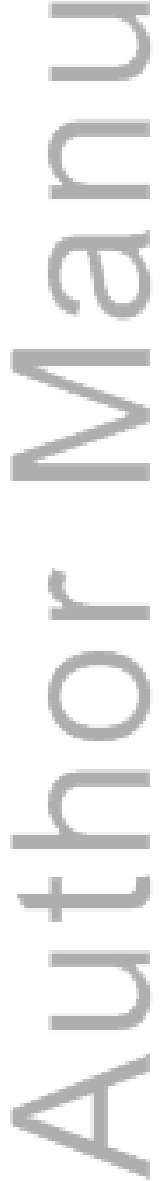

